January 2014

\title{
Westgate Shootings: An Emergency Department Approach to a Mass-casualty Incident
}

Benjamin Wachira

Aga Khan University, benjamin.wachira@aku.edu

Ramadhani Abdalla

Aga Khan University

Lee Wallis

University of Cape Town

Follow this and additional works at: http://ecommons.aku.edu/eastafrica_fhs_mc_emerg_med Part of the Emergency Medicine Commons

\section{Recommended Citation}

Wachira, B., Abdalla, R., Wallis, L. (2014). Westgate Shootings: An Emergency Department Approach to a Mass-casualty Incident. Prehospital and Disaster Medicine, 29(5), 538-541.

Available at: http://ecommons.aku.edu/eastafrica_fhs_mc_emerg_med/9 


\title{
Westgate Shootings: An Emergency Department Approach to a Mass-casualty Incident
}

\author{
Benjamin W. Wachira, MBChB, Dip PEC (SA), MMed EM, FCEM (SA); ${ }^{1}$ \\ Ramadhani O. Abdalla, MBBS; ${ }^{1}$ Lee A. Wallis, MBChB, Dip PEC (SA), MMed EM, FCEM (SA) ${ }^{2}$
}

1. Aga Khan University Hospital, Nairobi, Nairobi, Kenya

2. University of Cape Town, Rondebosch, Cape Town, South Africa

Correspondence:

Benjamin W. Wachira, MBChB Dip PEC

(SA), MMed EM, FCEM (SA)

Accident and Emergency Department

Aga Khan University Hospital - Nairobi

P.O. Box 30270

Nairobi 00100 Kenya

E-mail: benjamin.wachira@aku.edu

Conflicts of interest: The authors have no conflicts of interest to report.

Keywords: disaster planning; emergency preparedness; Kenya; terrorism

\author{
Abbreviations: \\ AKUH;N: Aga Khan University Hospital, \\ Nairobi \\ ED: emergency department \\ HDU: high dependency unit \\ HICS: Hospital Incident Command System \\ ICU: intensive care unit \\ MIMMS: Major Incident Medical \\ Management and Support \\ OR: operating room
}

Received: February 27, 2014

Accepted: June 9, 2014

doi:10.1017/S1049023X1400096X

\begin{abstract}
:
At approximately 12:30 PM on Saturday September 21, 2013, armed assailants attacked the upscale Westgate shopping mall in the Westlands area of Nairobi, Kenya. Using the seven key Major Incident Medical Management and Support (MIMMS) principles, command, safety, communication, assessment, triage, treatment, and transport, the Aga Khan University Hospital, Nairobi (AKUH,N) emergency department (ED) successfully coordinated the reception and care of all the casualties brought to the hospital.

This report describes the AKUH,N ED response to the first civilian mass-casualty shooting incident in Kenya, with the hope of informing the development and implementation of mass-casualty emergency preparedness plans by other EDs and hospitals in Kenya, appropriate for the local health care system.
\end{abstract}

Wachira BW, Abdalla RO, Wallis LA. Westgate shootings: an emergency department approach to a mass-casualty incident. Prehosp Disaster Med. 2014;29(5):1-4.

\section{Introduction}

At approximately 12:30 PM on Saturday, September 21, 2013, armed assailants attacked the upscale Westgate shopping mall in the Westlands area of Nairobi, Kenya. ${ }^{1}$ Overall, more than 175 people were injured and 67 people died. Casualties were rushed to the nearby hospitals by private ambulance services that had responded to the incident. Using Major Incident Medical Management and Support (MIMMS) principles, ${ }^{2}$ the Aga Khan University Hospital, Nairobi (AKUH,N) emergency department (ED) successfully coordinated the reception and care of the 65 casualties brought to the hospital.

The AKUH,N is a Joint Commission International-accredited private university hospital located less than three kilometers away from the Westgate shopping mall. ${ }^{3}$ It is a Level I trauma facility with over 300 beds. The ED has 24 beds and a resuscitation room which is equipped with two monitored beds and a fully stocked resuscitation trolley. The ED sees over 60,000 patients per year. Portable X-ray and ultrasound are immediately available from the radiology department. The computed tomography scanner is located next to the ED. There are five operating theatres, with specialized theatres for neurosurgery, orthopedics, and cardiac surgery. In addition, the hospital has an 11-bed high dependency unit (HDU) and a 20-bed intensive care unit (ICU). Bed occupancy in the hospital is routinely over $80 \%$.

Major Incident Medical Management and Support exists to teach the nature and management of a major incident and how to deliver the medical support needed at the scene of a major incident. At least nine major incidents have occurred in Kenya each year in the last five years. ${ }^{4}$ Many injured victims from the scene arrive in hospital untriaged and with barely any prehospital interventions. This essentially transfers the scene of the major incident to the ED. This was the rationale for the adoption of the MIMMS principles in the development of the AKUH,N ED mass-casualty management plan.

This report describes the AKUH,N ED's response to the first civilian mass-casualty shooting incident in Kenya. It identifies system processes that optimized the use of resources and reduced critical mortality in the face of maximum surge. The purpose of this report is to inform the development and implementation of mass-casualty emergency preparedness plans by other emergency departments and hospitals in Kenya, appropriate for the local health care system. 
Report

Ethics Approval

The report was approved for publication by the Aga Khan University Hospital, Nairobi after review and exemption from scientific and ethics review as per the institutional research policy.

\section{Emergency Department Response}

The AKUH,N has a hospital-wide mass-casualty management plan that was developed by the hospital's emergency preparedness committee based on the California Emergency Medical Services Authority Hospital Incident Command System (HICS). ${ }^{5}$ The HICS is an incident command system designed for hospitals of all sizes with tools needed to advance their emergency preparedness and response capability - both individually and as members of the broader response community.

The specific ED mass-casualty management plan falls within the operations section of the hospital's plan as shown in Figure 1.

The emergency preparedness committee conducts training for all new employees, refresher training and skills check for all current employees, and holds annual hospital-wide drills. The specific ED mass-casualty management plan is based on the seven key MIMMS principles: command, safety, communication, assessment, triage, treatment, and transport.

\section{Command}

The ED nurse manager had overall responsibility for the department. The manager facilitated all the services in the ED and ensured close communication and cooperation between them. Some of the services included triage and treatment, porter services, cleaning services, and provision of medical supplies. The manager also provided the link with the rest of the hospital administration as per the HICS principles.

\section{Safety}

The 1-2-3 of safety is of self, scene (the ED), and survivors. Staff safety in the ED was assured by immediate provision of personal protective equipment (gowns, gloves, and masks).

Safety of ED was achieved by effective control of all the access points into the ED at the onset of the major incident activation. Armed security personnel were deployed to the hospital and a security guard was placed at all entry points to the ED. Only authorized hospital personnel were allowed into the ED. A security guard was also placed at the entrance of the treatment area designated for immediate priority casualties to limit access to only authorized personnel. The security guards prevented those arriving to assist, the media, and the general public who wanted to observe from interfering with the response, or worse, becoming part of the incident.

Safety for the casualties was also guaranteed by dedicated treatment teams provided at all stages of their management as described below.

\section{Communication}

The quality of the first information that was passed from the scene to the ED was inadequate due to the lack of a wellcoordinated and reliable national disaster alert and coordination system. Information about the incident was obtained from media reports and witness accounts initially before the exact nature of the situation on scene was established. Due to the delay in obtaining this information, the hospital staff activation plan was only instituted as per the hospital's mass-casualty management

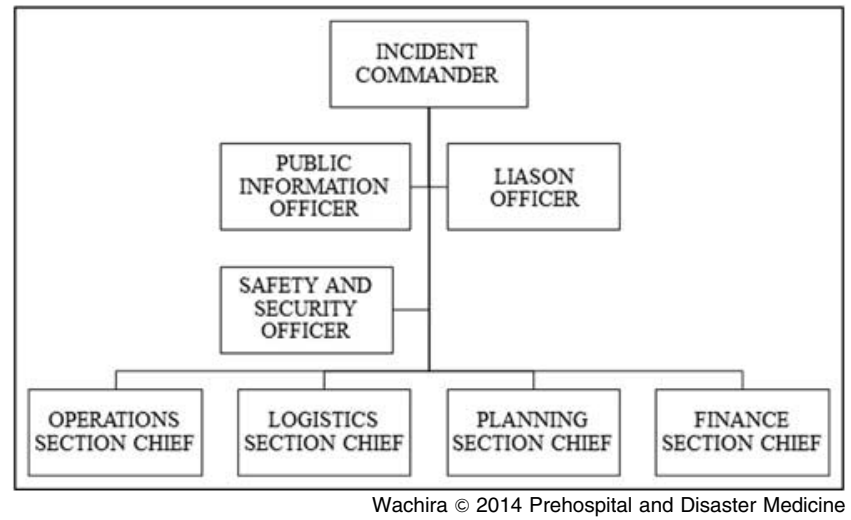

Figure 1. AKUH,N Incident Command Structure.

Abbreviation: AKUH,N, Aga Khan University Hospital, Nairobi.

plan when the exact nature of the incident was known. The majority of the staff who reported to the hospital did so voluntarily after hearing about the incident through media reports.

\section{Assessment}

The acronym METHANE (major incident, exact location, type of incident, hazards, access, number of casualties, and emergency services) is recommended in MIMMS as a reminder of the key information to be passed from the scene. The same acronym was used to assess the ED's preparedness once the major incident was declared by the hospital's incident commander. The exact location of the incident was known, along with its proximity to the hospital. The incident was initially thought to be a robbery from the initial reports, but the exact nature was realized as the first casualties arrived and more information was obtained from the scene. A hazard identified was the risk of armed perpetrators entering the premises. Additional security personnel were deployed as detailed above. Access and egress routes for ambulances to the ED were predesignated to prevent build-up of traffic. Unfortunately, due to the lack of a centralized ambulance dispatch system, there was no means of knowing the number of casualties at the scene or being transported to the ED. Due to the high numbers of patients seen in the ED daily, the department is usually wellstaffed, and with the activation of the major incident, additional staff members responded from the various departments.

\section{Triage}

Triage was established outside the door of the ED. A senior emergency physician was the ED triaging officer. Casualties were separated into different treatment priorities based on the history from the ambulance crew that brought in the casualty and a quick assessment as the casualty was transferred from the ambulance to the ED.

Casualties were prioritized into three categories: immediate (red), urgent (yellow), and delayed priority (green). Casualties with significant injuries to the head, neck, or torso were triaged "immediate priority," those with injuries to any other part of the body were triaged "urgent priority," and those with no obvious injuries were triaged "delayed priority."

Once triaged, the casualties triaged "immediate" and "urgent priority" were transferred to predesignated areas of the ED based on their triage category. Casualties triaged "delayed priority" did not access the ED, but were ushered through a separate entrance 


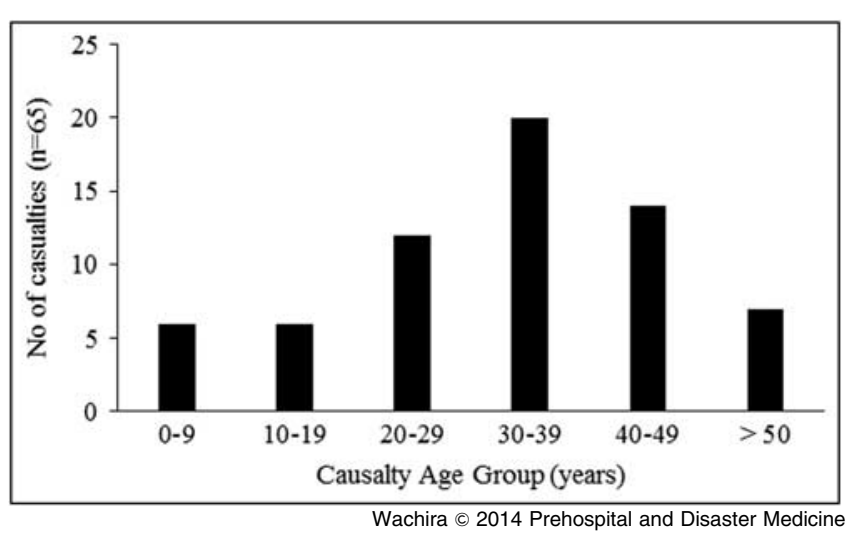

Figure 2. Age Distribution of Casualties

to the casualty clearing station that was located in a separate section of the hospital, close to the ED.

Once in the ED, casualties were retriaged after the primary and secondary surveys and resuscitation was done by the treatment teams and more information was available. Patients whose triage status changed were then moved to the appropriate predesignated section of the ED based on their new triage status in consultation with the triaging officer.

The chief surgical resident, now based in the ED, was the surgical triage officer. After stabilization by the treatment teams in the $\mathrm{ED}$, casualties who needed surgical intervention were triaged again by the surgical triage officer into priorities for transfer to the operating room (OR) for surgery. The officer was in constant communication with the OR teams and prioritized the casualties for OR based on the severity of their injuries. This was coordinated in conjunction with the ED triaging officer and the ED nurse manager.

\section{Treatment}

Overall, the AKUH,N ED received 65 casualties, mainly within the first six hours after the incident started. There were $58(89 \%)$ adult casualties ( $\geq 13$ years). Thirty-three (51\%) casualties were male. The age distribution of the casualties is shown in Figure 2.

Treatment teams consisting of a doctor and a nurse were formed at the beginning of the response. Additional staff that arrived were paired similarly. These teams were distributed out to four designated areas across the hospital based on their expertise. The first group of treatment teams was based in the ED. After triage, each casualty was assigned to a specific team who then did the primary and secondary surveys as per the American College of Surgeons Advance Trauma Life Support protocols ${ }^{6}$ and resuscitated the casualties appropriately. The second group was designated to the radiology department where they re-evaluated the casualties that were sent there from the ED and determined and prioritized the required imaging. A third group comprised of doctors mainly from the surgical department was designated to the surgical holding area, located next to the ED. All casualties coming back from radiology were reviewed in the surgical holding area and either admitted or sent to the casualty clearing station for the discharge processes. The final group was based in the casualty clearing station. Casualties who were triaged "delayed priority" and casualties designated for discharge from either the ED or the surgical holding area were reviewed here and all the necessary documentation and discharge plans made.

\begin{tabular}{|l|c|}
\hline Injury & Number of Casualties $\left(\mathbf{n}=\mathbf{4 0} \mathbf{~}^{\mathbf{a}}\right.$ \\
\hline Head Injury & 1 \\
\hline Facial Injury & 2 \\
\hline Chest Trauma & 4 \\
\hline Abdomen & 4 \\
\hline Spine & 2 \\
\hline Extremity Fractures & 9 \\
\hline Soft Tissue Wounds & 12 \\
\hline
\end{tabular}

Table 1. Injuries Sustained by Casualties Admitted from the Westgate Incident

${ }^{a}$ Some casualties had more than one injury.

Twenty-five casualties (38\%) were treated in the ED for soft tissue injuries and discharged on the same day. Forty casualties $(62 \%)$ were admitted into the hospital, three to the ICU, three to HDU, and the rest to the surgical wards. The injuries sustained by casualties admitted to the hospital from the Westgate incident is shown in Table 1.

Of the admitted casualties, $30(75 \%)$ needed surgery, more than half of them $(53 \%, \mathrm{n}=16)$ required multiple surgeries. Nineteen casualties (63\%) were operated on within 24 hours of the incident.

The median duration of stay of all admitted casualties was five days (range, 4-14). One casualty who was six months pregnant was brought in deceased and another casualty succumbed to injuries the following day post surgery in the ICU.

\section{Transport}

Flow of casualties from the ED and through the hospital was maintained by the porters who were made readily available on activation of the major incident. This avoided crowding in the $\mathrm{ED}$ and other sections of the hospital (eg, radiology). On arrival to the ED, casualties were assessed quickly, stabilized, and transferred from the ED either to radiology, OR, or the casualty clearing station. Casualties coming back from radiology went to the surgical holding area from where they were managed appropriately. By creating a one-directional flow of casualties through the ED, the department was always prepared to receive more casualties who may have still been coming from the scene.

\section{Discussion}

This is the first description of the emergency management of a masscasualty incident in a Kenyan hospital. The purpose of this report is to inform the development and implementation of mass-casualty emergency preparedness plans for EDs and hospitals in Kenya.

At least nine major incidents have occurred in Kenya each year in the last five years. ${ }^{4}$ The repetitive nature of these incidents recently, with a high number of deaths and injuries, suggests that all EDs in Kenya need to be adequately prepared to handle mass-casualty incidents.

Preparedness to take action is the prime instrument for reducing morbidity and mortality from mass-casualty incidents. Development of an integrated mass-casualty emergency preparedness plan should be a multi-departmental process, involving different departments in 
the hospital. With management of everyone's roles, and agreement on the command and control structures, preparedness capacity can be built and streamlined, improving coordination during major incidents.

Evidence from recurrent major incidents in the country should inform the training of all ED staff in major incident medical management and support and the development of integrated hospital and ED mass-casualty emergency preparedness plans. Key coordination hubs and standard operating procedures should also be established and tested with comprehensive drills, so that the ED and the institution can be more prepared to act in major incidents.

The major limitation faced was the identification of casualties from the onset and tracking their flow through the hospital in the initial phase of the response. Though most casualties were able to provide a name or were identified by relatives when they arrived, there was no standard identification and tracking system specific to the casualties of the major incident. Though this did not interfere with their care as treatment teams managed the casualties at all times, there was a delay in providing timely information on the actual number and location of the casualties at

\section{References}

1. Webb S, Tomlinson S, Duell M. Kenyan president says mall siege is OVER: five terrorists dead and bodies trapped in the rubble after three stories of shopping centre collapse in raid. MailOnline. http://www.dailymail.co.uk/news/article-2430325/ Kenyas-president-Uhuru-Kenyatta-says-mall-siege-OVER-5-terrorists-dead.html. Accessed December 9, 2013.

2. Advanced Life Support Group, (eds). Major Incident Medical Management and Support: The Practical Approach at the Scene, 3rd ed. Chicester, United Kingdom: Wiley-Blackwell; 2011.

3. Google. California: Google Maps; 2013. http://goo.g1/maps/z8dkO. Accessed December 9, 2013. any given moment as they moved through the different sections of the hospital. A system is currently being worked out to find the best way to improve on this in the future.

\section{Conclusion}

This report describes the AKUH,N ED response during the Westgate mass-casualty shooting incident. Using the MIMMS principles of command, safety, communication, assessment, triage, treatment, and transport, the ED was able to successfully coordinate the reception and care of all casualties brought to the hospital after the shootings. Development and implementation of masscasualty emergency preparedness plans for EDs and hospitals in the country, based on recent major incidents, will greatly enhance the country's preparedness and response to major incidents.

\section{Acknowledgements}

The authors greatly appreciate all the staff at AKUH,N whose desire to help their own communities was truly inspirational. The authors wish to thank Dr. Nzisa Liku, who assisted with the data collection, Professor Niranjan Kissoon for his insight, and Dr. John Tole, who reviewed the final manuscript.

4. EMDAT.be [Internet]. Brussels: The International Disaster Database. CRED; 2009. http://www.emdat.be/search-details-disaster-list. Accessed December 10, 2013.

5. California Emergency Medical Services Authority, (eds). Hospital Incident Command System Guidebook. California USA: California Emergency Medical Services Authority; 2006.

6. American College of Surgeons Committee on Trauma. "Initial Assessment and Management". In: American College of Surgeons Committee on Trauma, (eds). Advanced Trauma Life Support, Student Course Manual. Chicago, Illinois USA: American College of Surgeons; 2012:2-28. 